\title{
Application Research of MOOC in Higher Education
}

\author{
Zhongbin $\mathrm{We}^{1, \mathrm{a}}$, Jing $\mathrm{Wu}^{1, \mathrm{~b}}$ and Xinlin $\mathrm{He}^{1, \mathrm{c}}$ \\ ${ }^{1}$ Mechanical and electrical technology department, Xijing University, Xi'an, China \\ a358825406@qq.com, b925884122@qq.com, ${ }^{\mathrm{c}} 153789939 @ q q . c o m$
}

Keywords: MOOC; Network curriculum; Network resources; Higher education; Mooc platform

\begin{abstract}
The MOOC emerged as a newly emerging things in the field of education, and the MOOC promote the development of higher education in our country. The MOOC brings together students, experts, or teaching assistants who are interested in learning. The MOOC is a form of free learning courses for learners around the world. The MOOC provides the high-quality curriculum resources for the global learners through the curriculum platform of various colleges and universities around the world. In this article, the development of MOOC course is introduced; the use of the MOOC resources is analyzed; the organization implementation is described for mooc; The Mooc curriculum outlook is pointed out. The MOOC provides convenience for China's higher education. The MOOC need to be further perfect in the profit model, the theoretical design and learning style.
\end{abstract}

\section{Development of MOOC Course}

MOOC is usually a massive open online courses or massive open online course, there are also some scholars as "lesson" desire ". In this article the MOOC translated into massive open online courses. MOOC brings together students interest in learning, experts, or teaching assistants [1]. As long as the basic learning equipment all over the world can register and access to the curriculum resources and curriculum content. Them based on the common learning goals and content, using a series of free access to network resources to provide or the content of the materials they need to institute, exchange of learning through social networks. MOOC collaboration space can be across many different platforms and technology. Such as MOOC participants can learn to create their own blog posts, to discuss different aspects of the problem, Twitter, etc. Canadian scholar George Siemens and Stephen Downes, opened in 2008, Connectivism and Connective Knowledge courses is considered to be the first MOOC courses [2]. This course learners can learn in free. Based on the associated with the course of socialism and the traditional network courses, course not rely on the learning management system of learning resources. This course let related communication is a theme, a week without teachers will provide study materials on the subject, and at the same time, it supports the participants use different learning tools to participate in the study, discussion and evaluation, including YouTube, Moodle, BBS, blog, etc. Then Siemens grain Downes, mouth opened PLENK (Personal Learning Envoriments Networks andKnowledge) courses. And courses in these characters can be said to be the leading MOOC [3]. These courses were set up, like this one in education on calm water of the lake threw a stone, not provoke chain without but led to more volatile, can be called a sea, where cause reaction of global education.

Massive open online courses is provided by the platform with the curriculum in the world, high-quality curriculum resources for the use of global learners free course form of learning. Of course providers have departments from well-known colleges and universities teaching team, well-known experts and professors, experts and scholars, etc., learners are all over the world every corner of the course, only have interest in learning and courses required skills to be able to participate in courses for self improvement [4]. Massive Open Online Course of MOOCS as shown in Fig. 1. 


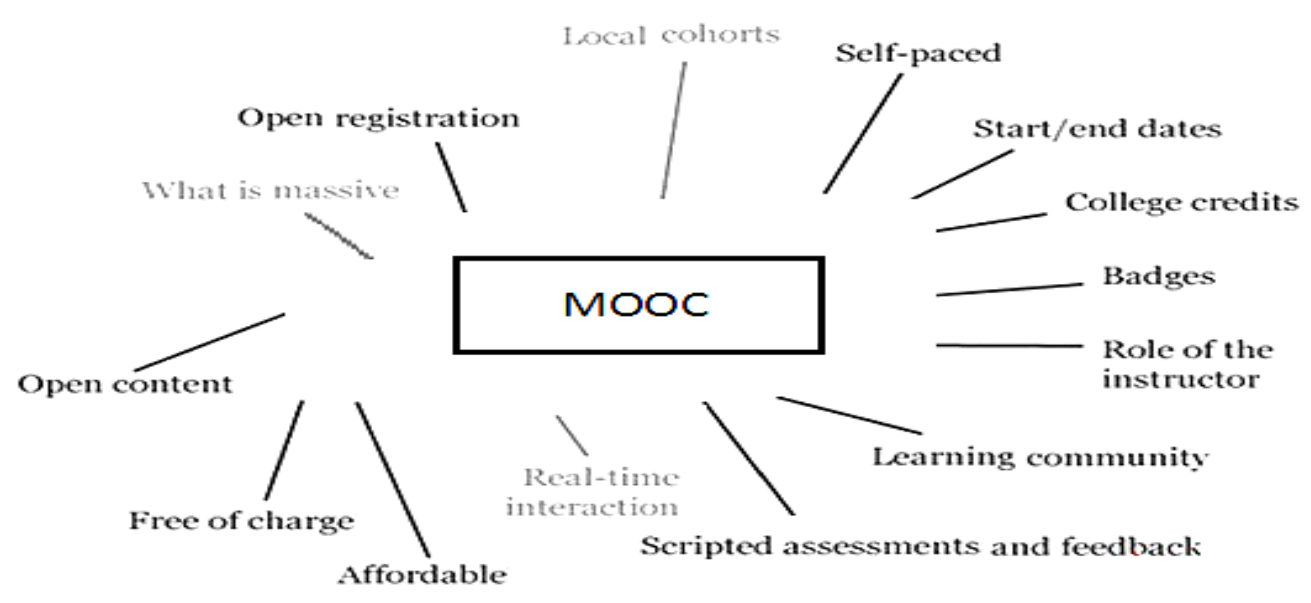

Figure 1. Massive Open Online Course of MOOCS

\section{MOOC Resources Analysis}

Three courses are belong to xMOOC type platform, so similar to the form of curriculum resources. From the perspective of a class instance to provide resource type, different forms of curriculum resources is not the same. But mainly video interpretation, with a small test in the video, curriculum reference materials or references provided in the form of links or PDF document, video subtitles are downloadable, etc.,

Course contents are mountain video, video resources generally in the form of a list shall be carried out in accordance with the teaching cycle. Video will be embedded in the test, students have mastered the knowledge degree can be timely feedback. Most of the course will provide a PDF notes or download courseware for students to learn. A few course has the requirement of teaching material, some courses will provide reading materials, references or reading reference links, students can learn according to their own situation the appropriate extension and depth [5].

Liberal arts and art course provides extended reading is relatively abundant, such as course reference reading, teaching reference books, etc.). In science and engineering course of exercises and homework form is more diverse, type of computer programming courses also provide a programming test sites such as auxiliary tools and platforms [6]. As a result of the course of mass learners, only by the teachers and teaching assistants to corrects students' papers is unrealistic. This automatic evaluation can not only improve the test efficiency, and timely evaluation result feedback to the learner, easy to modify and perfect.

\section{To Organize the Implementation of MOOC Course}

Teaching Process. Massive open online courses for learners' learning time no mandatory requirements, learners can freely arrange course schedule, but the overall course is set the start time and the session time, also in the course, set up a job submission deadline is not completely from the mountain. When the teacher began to start the course on the platform of syllabus and relevant time [7]. In the teaching process are carried out in accordance with the syllabus, follow-up of any change in the course BBS or inform the learners in email form.

The teaching pattern, three big platform is outside the extension of the teaching mode. Its teaching process and the professor of the physical classroom in colleges and universities, practice, test form, concrete form is a good teacher to record these video lectures, the average time for 3-30 minutes, or the end of the video in the video will have relevant test, but the evening, teacher will also require students to each learning cycle and the mid-term final complete the corresponding test. Course platform server will automatically record based on learners' learning behavior as evaluation results. Some teachers also provides special Office Hours to answer the problems of students. 
In the teaching process schedule, with different colors represent different content, and a detailed explanation. Weekly progress, practice and assignments in the form of be clear at a glance. Finally, to illustrate the statistical approach to the result, the learners can learn about the proportion of various grades and to get the certificate at ordinary times need to reach the final result, so that learners to set goals [8].

Evaluating. The selected courses in the instance evaluation form mainly has the teacher assessment and peer assessment, self assessment, etc. Among them, the peer evaluation is also known as peer mutual or peer evaluation, learners to jump out the learner's role is made up of course, try to the teacher's role to the evaluation of students, on the basis of course teachers evaluation gauge, the evaluation is anonymous evaluation of the self as a supplementary evaluation way. Teacher evaluation is mainly based on learners course assignments submitted at ordinary times and the final exam is calculated according to certain proportion the final score.

After the analysis of the selected typical course summary, can be found:

(1) from the perspective of the assessment project of grades, most courses in addition to have homework and quiz at ordinary times, science and engineering courses also include some programming assignments or demonstration operation [9]. Science and engineering courses usually pay more attention to examine test and homework after class, some as high as $60 \%$, and the literature, the arts courses will include some reading and writing exercises, etc. Some will course participation and peer evaluation also included usually scored in the project.

(2) According to the proportion of the final score can be calculated in the table course final average proportion is $22 \%$, it learned that MOOC curriculum attaches great importance to the study at ordinary times, the final exam is not the decisive role. This to a certain extent, also reflects the MOOC requires learners have strong ability of autonomous learning, to finish the course content, course evaluation pay more attention to grades, process evaluation.

(3) the most MOOC courses from two aspects of grades and final grade appraised. Some courses don't arrange the final exam, or the final score of a smaller proportion of this kind of course for more operational strong in science and engineering course, examination form comprehensive variety of classes or grades.

(4) in the course "certificate according to the learner's final composite scores, can achieve different levels of certificate, certificate can be obtained up to $60 \%, 85 \%$ or $90 \%$ of the outstanding person certificate can be obtained. The hierarchical form of certificate can promote the test involved in learning, improve the learners' participation [10].

(5) the course "form for the comprehensive score lowest of $60 \%$ or more to get certificate or a certificate signed by the teacher course, said the task to complete the course of learning.

\section{MOOC Course}

Nature of massive open online course platform has two kinds: one kind is commercial, is a kind of public interest. Coursera and Udacity courses is to allow learners to completely free of learning, let alone is non-profit edx platform, but of course platform where working capital source, free pattern will continue for a long time, these are all need to discuss problems, is the need to solve the challenge.

From the point of the current curriculum operation, mostly rely on the wind investment gold and non-profit foundation, colleges and universities cooperation support form of operation, such as Coursera in again after the success of the first round for the second round of funding, Leam the vc company for Capital, and the world bank affiliate, the international finance corporation (IFC), the for-profit education group of Laureate, support, etc. But currently curriculum operation profit model did not have a clear form, especially for a project funded by the government, finance large sums of money to support, not a long-term solution, technical director of Shanghai education commission information center, the cost of the public class platform mainly from the education commission of Shanghai, but towards marketization is the inevitable development trend. 
Udacity joint Georgia institute of technology cooperation with America's mobile operators AT\&T, learners' learning task can obtain a master's degree in computer science, Udacity platform will provide for free for learners to gain the degree of learning materials, but need to pay a fee, the learner is about $\$ 7000$, but relatively as qualified students $\$ 40000$ tuition, this form of course fee much cheaper.

\section{Outlook of MOOC Course}

MOOC emerged as a newly emerging things in the field of education, different scholars to research the depth and breadth of its are very different. The further study of MOOC should consider the following content. (1) about the MOOC learning design. Different forms of learning, MOOC how to help learners to improve learning effect, MOOC can adopt what kind of teaching design or technical support for learners to provide a more effective learning experience are to be further discussed. (2) research on the profit pattern of MOOC. Professor offer free MOOC spend a lot of time and effort, teachers offer continuous power come from? MOOC the development, maintenance, guiding, operations, such as high costs borne by the who, the sustainable development of the need to find a real business model. (3) about the MOOC education theory and education method. Three courses in the platform close to the traditional classroom teaching form, whether MOOC itself has the unique teaching mode and teaching method. (4) learning experience, the study of MOOC. Higher education in the future how to better serve the society, what kind of students, subject, learning environment, learning content is effective to adopt MOOC form, MOOC learners' learning motivation and learning what are the differences in performance influence factors. (5) about the negative impact of MOOC research. Now most people are recognized for MOOC or neutral, but its negative effect about the existence of education field, what are these negative effects, the researchers can try to make in-depth research of interest.

\section{References}

[1] Benoit Minogue: Higher Education Spending and Output-Complexity of Relationship, Peking University Education review, Vol. 2 (2013), 60.

[2] L. Yuan, Stephen Powell, H. L. Ma: International Status Quo Analysis of Massive Open Online Courses Closed, Vol. 84(2013) No.3.

[3] B. C. Ji: Our Country's Higher Education Scale Forecast Analysis in 2020, Vol. 1 (2011) No. 1, p. 305.

[4] Z. Wang, J. X. Tian: Inheriting Hin for Class in Our Country the Development of the SWOT Analysis, Journal of the new curriculum (below), Vol.7 (2013)No.7.

[5] W. X. Cai, J. Wang: The First Year of MOOC, Vol.4 (2012), P. 16-18.

[6] H. Y. Liu: U DP Proportion Higher Education and Social Policy Research, Vol. (2012), P. 27-28.

[7] J. B. Wang, H.T. Yang: New Field of Overseas Investment-New Trend of Transnational Higher Education (Dong Yue Review, China, 2012)

[8] Henry m. levin. Education How to Adapt to Future-Background of American Education, Peking University Education Review, Vol. 2 (2013), p. 2-3.

[9] P.Wang: New Development and Application of Large-Scale Online Open Courses, Vol. 19(2013) No.1.

[10] Wang QJ, Wu JT. "Thoughts on Integrating Innovation and Entrepreneurship Education into the Whole Process of Talent Training”, Advances in Computer Science Research, vol.25, pp.149-152, 2015. 
[11]G. P. Feng: Transnational Education-International Comparative Study (Shanghai People's Publishing House, China ,2010) 